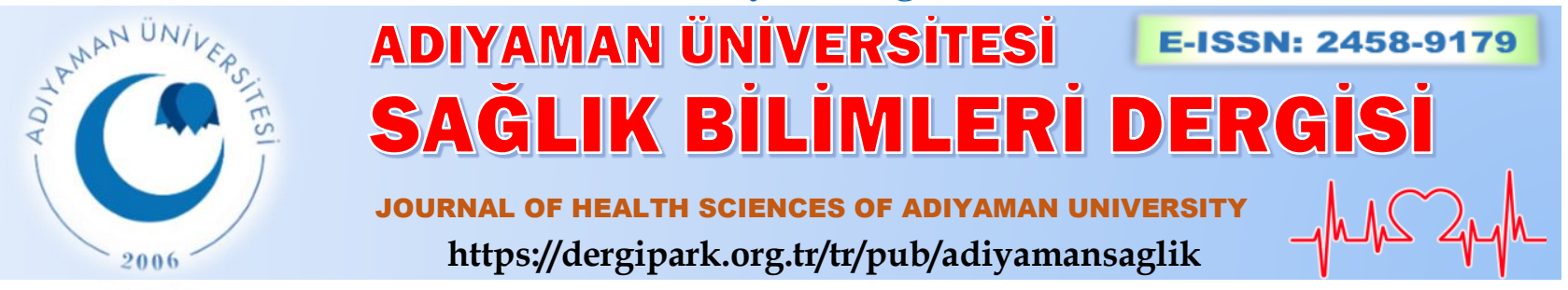

Systematic Reviews and Meta Analysis/Sistematik Derlemeler ve Meta Analiz

\title{
Bireyselleştirilmiş gelişimsel bakımda anne sesi ve anne kalp sesinin yenidoğan bebekler üzerindeki etkisinin incelenmesi: sistematik derleme
}

\section{Investigation of the effect of maternal voice and maternal heartbeat voice on newborn babies in individualized developmental care: a systematic review}

\author{
Suat TUNCAY $@$ (D), Abdullah SARMAN ${ }^{2}$ \\ ${ }^{1}$ Bingöl Üniversitesi, Sağlık Bilimleri Fakültesi, Çocuk Sağlığı ve Hastalıkları Hemşireliği Anabilim Dalı, 12000, Bingöl-Türkiye \\ ${ }^{2}$ Bingöl Üniversitesi, Sağlık Hizmetleri Meslek Yüksekokulu, İlk ve Acil Yardım Programı, 12000, Bingöl-Türkiye
}

Atıf gösterme/Cite this article as: Tuncay S, Sarman A. Bireyselleştirilmiş gelişimsel bakımda anne sesi ve anne kalp sesinin yenidoğan bebekler üzerindeki etkisinin incelenmesi: sistematik derleme. ADYÜ Sağlık Bilimleri Derg. 2020;6(3):357-366. doi:10.30569.adiyamansaglik.730806

$\ddot{\mathbf{O z}}$

Amaç: $\mathrm{Bu}$ araştırma, bireyselleştirilmiş gelişimsel bakımda anne sesi ve anne kalp sesinin yenidoğan bebekler üzerindeki etkisini özetlemek amacıyla planlandi.

Gereç ve Yöntem: Bu sistematik derlemede, 20052020 yılları arasında yayımlanan anne sesi ve anne kalp sesinin bebek üzerine etkisiyle ilgili çalışmalar incelendi. Veri tabanlarından 96 çalışmaya ulaşıldı. Tekrar eden ve başlığı uygun olmayan çalışmalar, Türkçe ya da İngilizce olmayan, fetüs üzerine olan, insan bebeği ve anne sesi ile anne kalp sesini incelemeyen çalışmalar bu araştırmanın kapsamından çıkarıldı. Toplam 16 çalışma araştırmaya dahil edildi.

Bulgular: Araştırmaya alınan çalışmaların gestasyon yaşı, ses düzeyi, anne sesine maruziyet süresi ve sıklığ1 açısından çok farklı sonuçları olduğu bulundu. Anne sesi ve kalp sesinin bebeklerin beslenme, davranış, stres ve beyin gelişimini olumlu etkilediği görüldü. Ağrı, konfor ve fizyolojik parametreler ile ilgili kesin sonuçlar elde edilemedi.

Sonuç: İyi tasarlanmış klinik denemelerde anne sesi ve anne kalp sesinin bebekler üzerinde etkili olduğu bulundu. $\mathrm{Bu}$ nedenle yenidoğan yoğun bakımlarda yatan bebekler için kullanılması önerilmektedir.

Anahtar Kelimeler: Anne kalp sesi; Anne sesi; Bireyselleştirilmiş gelişimsel bakım; Yenidoğan bebekler.

\begin{abstract}
Aim: This study was planned to summarize the effect of maternal voice and maternal heartbeat voice on newborn babies in individualized developmental care.

Materials and Methods: The effects of mother's voice and mother's heartbeat voice on the baby published between 2005-2020 was examined in this systematic review. 96 studies have been reached from databases. Repetitive and unappropriated title studies, studies that are not in Turkish or English, on fetus studies, and do not examine the human baby and mother voice and mother heartbeat voice were excluded from the scope of this study. A total of 16 studies were included in the research.

Results: The studies included in the research were found to have very different results as a gestational age, sound level, duration and frequency of exposure to maternal voice. Mother's voice and heartbeat voice were found to affect babies' nutrition, behavior, stress and brain development positively. There were no definitive results regarding pain, comfort, and physiological parameters.

Conclusion: In well-designed clinical trials, maternal voice and maternal heartbeat voice were found to be very effective on babies. It is recommended to be used for babies lying in intensive care units

Keywords: Maternal heartbeat voice; Maternal voice; Individualized developmental care; Newborn babies.
\end{abstract}

Yazışma Adresi/Address for Correspondence: Suat TUNCAY, Bingöl Üniversitesi, Sağlık Bilimleri Fakültesi, 12000, BingölTürkiye, E-mail: suat.tuncay@gmail.com

Geliş Tarihi/Received:02.05.2020Ｋabul Tarihi/Accepted:24.06.2020

Yayım Tarihi/Published online:03.12.2020

Bu eser, Creative Commons Atıf-GayriTicari 4.0 Uluslararası Lisansı ile lisanslanmıştır. Telif Hakkı @ 2020 Adıyaman Üniversitesi Rektörlüğü 


\section{Giriş}

Yenidoğanlara verilen bakımın kalitesi yükseldikçe bebeklerin hayatta kalma oranları da artmaktadır. Koruyucu tıp uygulamalarının giderek artmas1 sayesinde hayatta kalan bebekler birtakım gelişimsel ve nöral bozukluklarla karşılaşmaktadır. Bireyselleştirilmiş gelişimsel bakım (BGB) uygulamaları ile bu bozukluklar ortadan kaldırılmaya ya da en aza indirilmeye çalışılmaktadır. ${ }^{1,2}$ Gelişimsel bakım; iyileştirici çevre, uyku-uyanıklık düzeninin sağlanması-güvenli uyku, gelişimsel destekleyici aktiviteler ve aile merkezli bakımı kapsamaktadır. Bunlardan ışık ve ses kontrolünü kapsayan iyileştirici çevre, yenidoğanın davranışlarının ve tüm alt sistemlerinin düzenlenmesi ile ilişkilidir. ${ }^{3}$

Yenidoğan bebeğin duyusal-fonksiyonel gelişimi için duyduğu sesin niteliği ve zamanı oldukça önemlidir. İntrauterin dönemde bebeğin duyduğu ses yaklaşı olarak 50 desibel (dB) civarındadır. Dünya Sağlık Örgütü (DSÖ), güvenli ses için gündüz $35 \mathrm{~dB}$, gece $30 \mathrm{~dB}$ düzeyini önerirken, Amerikan Pediatri Akademisi (APA) 50 dB'yi önermektedir. Yüksek sesler bebeğin gelişimini olumsuz etkilerken düşük frekanslı sesler bebeğin gelişimini olumlu etkilemektedir. $^{4-6}$ Fetüsün 26-28. haftadan itibaren seslere tepki verdiği kabul edilmektedir. Annenin çıkardığ amniyon sıvısına ulaşır. Amniyon sıvısına giren ses basıncı, doğrudan kranial boşluğa ve oradan koklear sıvılara ulaşarak bu sıvıları ileten kanallar tarafindan kafatasında titreşimler meydana getirmektedir. $\mathrm{Bu}$ nedenle, erken doğmuş bebeklerin maternal sese maruziyetinin kemik iletimi yoluyla gerçekleştiği düşünülmektedir. ${ }^{7,8}$

Yenidoğan bebeğin anne sesini ve anne kalp sesini tanımlayabildiği öngörülmektedir. ${ }^{7,8}$ Maternal ses maruziyeti standart gelişimsel bakım müdahalelerine dahil edilmemesine rağmen, araştırmacılar son on y1lda anne sesine maruz kalmanın bebeğin fizyolojik parametreleri üzerinde etkili olduğunu, bebeğe enerji verdiğini, uyarıcı rolü olduğunu, beslenme ve beyin gelişimini etkilediğini belirlemiştir. ${ }^{6}$ Buna rağmen ülkemizde yenidoğan hemşirelerinin
BGB uygulamalarının yeterli düzeyde olmadığ 1 görülmektedir. ${ }^{9}$ Özellikle anne sesi ve anne kalp sesinin etkisini belirleyen sinırlı sayıda çalışma bulunmuştur. ${ }^{10-17} \mathrm{Bu}$ nedenle araştırma, anne sesi ve anne kalp sesinin yenidoğan bebekler üzerindeki etkisini özetlemek amacıyla yapılmıştır.

\section{Gereç ve Yöntem}

\section{Araştırmanın tasarımı}

$\mathrm{Bu}$ sistematik derleme, Ocak 2005-Nisan 2020 yılları arasında yayımlanan çalışmaların sonuçlarını kapsamaktadır. $\mathrm{Bu}$ araştırmanın tasarımı; arama yöntemlerini, arama terimlerini, arama sinırlılıklarını, tekrarlı çalışmaların çıkarılmasını ve dışlanma kriterlerini içermektedir.

\section{Arama yöntemi}

$\mathrm{Bu}$ araştırmaya Ocak 2005'ten Nisan 2020'ye kadar olacak şekilde son on beş y1lda yayımlanan tüm ulusal ve uluslararası çalışmalar dahil edildi. "Maternal sound ve/veya voice", "preterm ve/veya infant", "newborn", "developmental care", "maternal heartbeat ve/veya heartsound" anahtar kelimeleri beraber ya da ayrı şekilde Google Akademik, Scopus, Pubmed ve Web of Science veri tabanlarından taratıldı. Arama sınırları Türkçe ve İngilizceden oluşmakta ve sadece insan üzerine olan çalışmaları kapsamaktadır.

\section{Arama sonuçları}

Veri tabanlarından ilgili anahtar kelimelerle yapılan tarama sonucunda 96 çalışmaya ulaşıldı. Tarama sonuçları iki yazar tarafindan kontrol edildi ve tekrar eden çalışmalar $(\mathrm{n}=12)$, başlığı uygun olmayan çalışmalar $(n=21)$, derleme çalışmaları $(n=4)$, dili Türkçe ya da İngilizce olmayan çalışmalar $(\mathrm{n}=2)$, fetüs üzerine etkileri inceleyen çalışmalar $(n=4)$, insan bebeği ve anne sesi ile anne kalp sesini incelemeyen çalışmalar $(n=37)$ bu araştırmanın kapsamından çıkarıldı. 2005 yılı öncesinde yayımlanan çalışmalar göz ardı edilerek araştırma tamamlandı (Şekil 1).

\section{Metodolojik değerlendirme}

Dahil edilen çalışmalar için kanıta dayalı uygulamalar piramidinden yararlanıld $1 .^{18}$ 
Yüksek kanıt düzeyi sunan randomize kontrollü çalışmalar, kohort çalışmaları, deneysel çalışmalar ile yarı deneysel çalışmalar ve iyi düzenlenmiş vaka kontrol çalışmalarından faydalanıldı. Tanımlayıcı, niteliksel ve gözlemsel çalışmalar araştırmanın kapsamı dışında bırakıldı.

\section{Verilerin tanımlanması}

Araştırmaya 16 çalışma dahil edildi (Tablo 1). Araştırmada; çalışmaların türü, örneklemi, çalışmadaki bebeklerin gestasyon yaşı, anne sesi ve kalp sesi uygulamas1, anne sesi desibel düzeyi, müdahale grubu ve müdahale grubunda uygulanan girişim, kontrol grubu ve kontrol grubunda uygulanan girişim, anne sesi süre ve sıklığı, anne sesinin etkinliği ve ana bulguları incelendi.

\section{Verilerin değerlendirilmesi}

$\mathrm{Bu}$ araştırmada anne sesi ve anne kalp sesinin bebekler üzerindeki etkisini inceleyen çalışmalar ilk olarak; çalışmalardaki klinik düzen, gestasyon yaşı, anne sesi desibel düzeyi, anne sesi uygulanış yöntemi, müdahale ve kontrol grubu uygulama özellikleri, anne sesi ve anne kalp sesi maruziyetinin süre ve sıklığına göre incelendi. İkincil olarak; anne sesi ve kalp sesi maruziyetinin ağrı, fizyolojik özellikler, beslenme, davranış, stres ve beyin gelişimi üzerindeki etkileri tartışıldı.

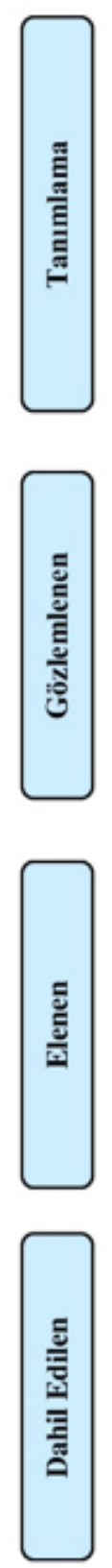

Scopus, Pubmed, Google Akademik ve Web of Science veritabanlarından taranan çalışmalar $(\mathrm{n}=96)$
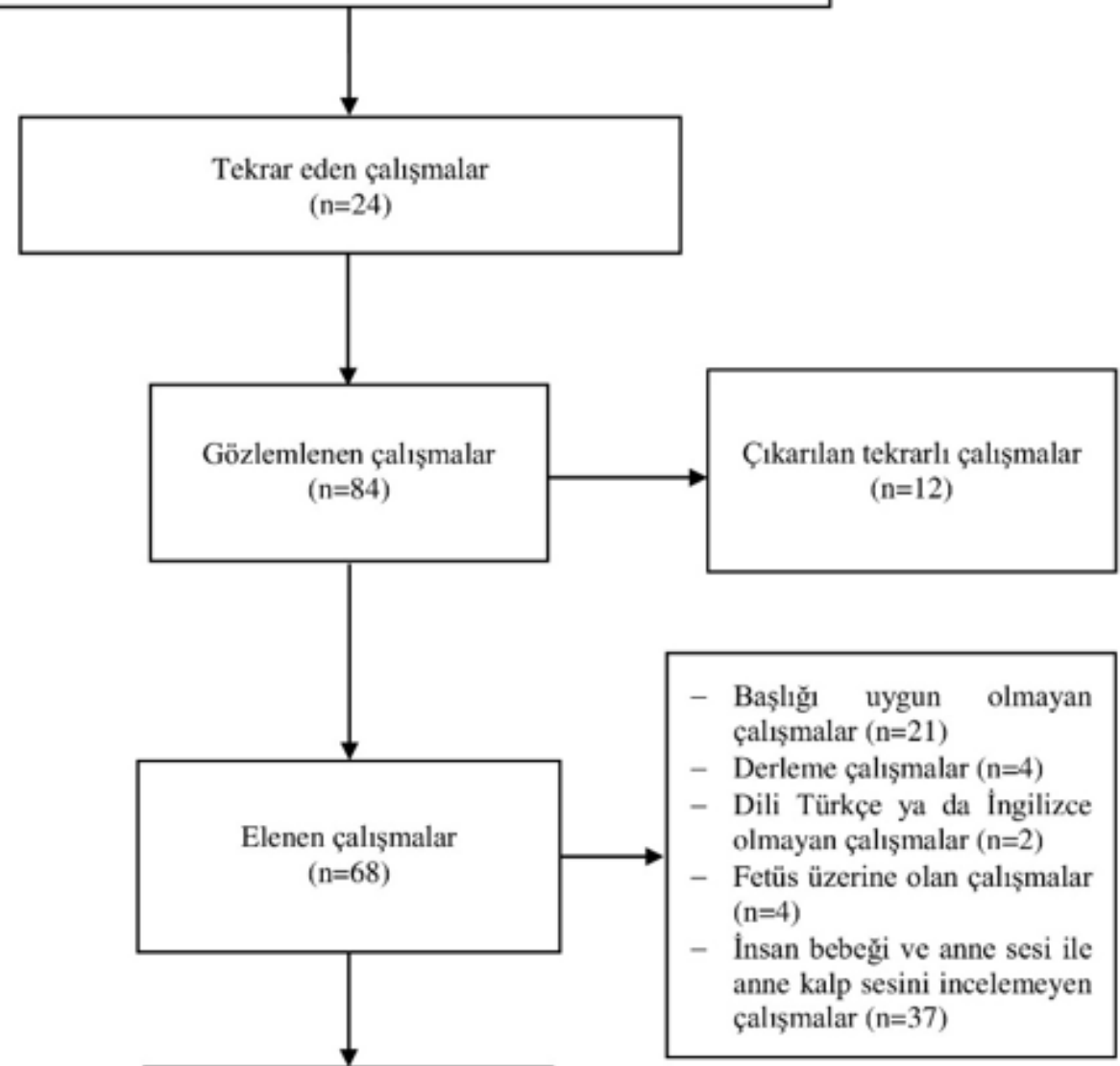

Değerlendirmeye alınan çalışmalar $(\mathrm{n}=16)$

Şekil 1. Araştırmaya alınan çalışmaların akış şeması 
Tablo 1. İncelenen çalışmaların özellikleri ve genel bulguları.

\begin{tabular}{|c|c|c|c|c|c|c|c|c|c|c|c|}
\hline $\begin{array}{l}\text { Çalışma } \\
\text { Yazarları }\end{array}$ & $\begin{array}{l}\text { Çalışma } \\
\text { Türü }\end{array}$ & Örneklem & $\begin{array}{l}\text { Gestasyon } \\
\text { Yaşı }\end{array}$ & $\begin{array}{l}\text { Anne } \\
\text { Sesi ve } \\
\text { Kalp } \\
\text { Sesi } \\
\text { Özelliği } \\
\end{array}$ & $\begin{array}{l}\text { Desibel } \\
\text { Aralığı } \\
\text { (dB- } \\
\text { dBA**) }\end{array}$ & $\begin{array}{l}\text { Müdahale } \\
\text { Grubu ve } \\
\text { İşlem }\end{array}$ & $\begin{array}{l}\text { Kontrol } \\
\text { Grubu }\end{array}$ & $\begin{array}{l}\text { Süre } \quad \text { (Her } \\
\text { Bir İşlem } \\
\text { İçin) }\end{array}$ & Sıklık & Etkinlik & Ana Bulgular \\
\hline $\begin{array}{l}\text { (Alemdar, } \\
\text { 2018) }\end{array}$ & RKÇ* & 123 bebek & 30. hafta & $\begin{array}{l}\text { Ses } \\
\text { kayit } \\
\text { cihaz1 }\end{array}$ & $45 \mathrm{~dB}$ & $\begin{array}{l}\text { Anne sesi, } \\
\text { venöz } \\
\text { girişim }\end{array}$ & $\begin{array}{l}\text { Standart } \\
\text { bakim }\end{array}$ & 16 dakika & $\begin{array}{l}\text { İşlem } \\
\text { sirası, } \\
\text { yalnızca } \\
\text { bir kez }\end{array}$ & Ağr1 ve konfor & $\begin{array}{lr}\text { Anne } & \text { sesinin, } \\
\text { invaziv } & \text { girişimler } \\
\text { sırasında } & \text { ağrı ve } \\
\text { konfor } & \text { üzerine } \\
\text { etkisi } & \text { istatistiksel } \\
\text { olarak } & \text { zayıf } \\
\text { bulundu } & \\
\end{array}$ \\
\hline $\begin{array}{l}\text { (Chirico ve ark., } \\
\text { 2017) }\end{array}$ & $\begin{array}{l}\text { Prospektif, } \\
\text { deneysel } \\
\text { çalışma }\end{array}$ & 40 bebek & 29-36 hafta & $\begin{array}{l}\text { Ses } \\
\text { kayit } \\
\text { cihazı }\end{array}$ & $50-55 \mathrm{~dB}$ & $\begin{array}{l}\text { Anne sesi, } \\
\text { topuk kanı } \\
\text { alımı }\end{array}$ & $\begin{array}{l}\text { Standart } \\
\text { bakım }\end{array}$ & 30 dakika & $\begin{array}{l}\text { İşlem } \\
\text { sirası, } \\
\text { yalnızca } \\
\text { bir kez }\end{array}$ & $\begin{array}{l}\text { Ağrı ve } \\
\text { fizyolojik } \\
\text { etkiler (kalp } \\
\text { atış hızı, } \\
\text { oksijen } \\
\text { satürasyonu, } \\
\text { solunum hızı, } \\
\text { tansiyon) }\end{array}$ & $\begin{array}{l}\text { Anne sesinin } \\
\text { yalnızca ağrı ve } \\
\text { oksijen } \\
\text { satürasyonu } \\
\text { üzerinde etkili } \\
\text { olduğu bulundu }\end{array}$ \\
\hline $\begin{array}{l}\text { (Alemdar ve } \\
\text { Tüfekci, 2017) }\end{array}$ & RKÇ & 62 bebek & 28-36 hafta & $\begin{array}{l}\text { Ses } \\
\text { kayit } \\
\text { cihazı }\end{array}$ & $45 \mathrm{~dB}$ & $\begin{array}{l}\text { Anne kalp } \\
\text { sesi, } \\
\text { aspirasyon } \\
\text { işlemi }\end{array}$ & $\begin{array}{l}\text { Standart } \\
\text { bakim }\end{array}$ & 15 dakika & $\begin{array}{l}\text { İşlem } \\
\text { öncesi, } \\
\text { siras1 ve } \\
\text { sonrasi } \\
\text { toplam } \\
\text { üç kez }\end{array}$ & $\begin{array}{l}\text { Fizyolojik } \\
\text { etkiler (kalp } \\
\text { atımı, solunum } \\
\text { hız1, } \\
\text { satürasyon) }\end{array}$ & $\begin{array}{l}\text { Anne kalp sesi } \\
\text { satürasyon } \\
\text { üzerinde etkili } \\
\text { olurken kalp atım } \\
\text { ve solunum hızı } \\
\text { üzerinde etkisi } \\
\text { olmadığı bulundu }\end{array}$ \\
\hline $\begin{array}{l}\text { (Webb ve ark., } \\
\text { 2015) }\end{array}$ & $\begin{array}{l}\text { Deneysel } \\
\text { çalışma }\end{array}$ & 40 bebek & 25-32 hafta & $\begin{array}{l}\text { Ses } \\
\text { kayıt } \\
\text { cihazı }\end{array}$ & $58 \mathrm{dBA}$ & $\begin{array}{l}\text { Anne sesi } \\
\text { ve anne } \\
\text { kalp sesi }\end{array}$ & $\begin{array}{l}\text { Standart } \\
\text { bakım }\end{array}$ & 45 dakika & $\begin{array}{l}\text { Bir ay } \\
\text { boyunca } \\
\text { günde } \\
\text { dört defa }\end{array}$ & Beyin gelişimi & $\begin{array}{l}\text { Anne sesi ve kalp } \\
\text { sesinin beyin } \\
\text { gelişimini olumlu } \\
\text { etkilediği bulundu }\end{array}$ \\
\hline $\begin{array}{l}\text { (Chorna ve ark., } \\
\text { 2014) }\end{array}$ & $\begin{array}{l}\text { Prospektif, } \\
\text { RKÇ }\end{array}$ & 94 bebek & 34-36 hafta & $\begin{array}{l}\text { Ses } \\
\text { kayıt } \\
\text { cihazı }\end{array}$ & Belirtilmedi & Anne sesi & $\begin{array}{l}\text { Standart } \\
\text { bakım }\end{array}$ & 15 dakika & $\begin{array}{l}\text { Beş gün } \\
\text { boyunca } \\
\text { günde } \\
\text { bir defa }\end{array}$ & Beslenme & $\begin{array}{l}\text { Anne sesinin oral } \\
\text { beslenmeyi } \\
\text { etkilediği bulundu }\end{array}$ \\
\hline $\begin{array}{l}\text { (Rand ve Lahav, } \\
\text { 2014) }\end{array}$ & $\begin{array}{l}\text { Kohort } \\
\text { çalışma }\end{array}$ & 20 bebek & 25- 32 hafta & $\begin{array}{l}\text { Ses } \\
\text { kayıt } \\
\text { cihazı }\end{array}$ & $57 \mathrm{dBA}$ & Anne sesi & & 30 dakika & $\begin{array}{l}\text { Günde } \\
\text { dört } \\
\text { defa, bir } \\
\text { ayda } 24 \\
\text { gün }\end{array}$ & \begin{tabular}{l}
\multicolumn{2}{l}{ Fizyolojik } \\
etkiler (kalp \\
atımı)
\end{tabular} & $\begin{array}{l}\text { Anne sesinin kalp } \\
\text { atımını } \\
\text { stabilleştirdiği } \\
\text { bulundu }\end{array}$ \\
\hline
\end{tabular}




\begin{tabular}{|c|c|c|c|c|c|c|c|c|c|c|c|}
\hline $\begin{array}{l}\text { (Dorn ve ark., } \\
\text { 2014) }\end{array}$ & Blok RKÇ & 62 bebek & 30-37 hafta & $\begin{array}{l}\text { Ses } \\
\text { kayit } \\
\text { cihazı }\end{array}$ & $55-65 \mathrm{~dB}$ & Anne sesi & $\begin{array}{l}\text { Standart } \\
\text { bak1m }\end{array}$ & Bir saat & $\begin{array}{l}\text { Günde } \\
\text { yedi } \\
\text { defa, } 21 \\
\text { günde üç } \\
\text { gün }\end{array}$ & $\begin{array}{l}\text { Aktivite, } \\
\text { dinlenme, } \\
\text { uyku ve } \\
\text { kortizol düzeyi }\end{array}$ & $\begin{array}{l}\text { Anne sesi uyku ve } \\
\text { uyanıklık } \\
\text { döngüsünü olumlu } \\
\text { etkilerken aktivite } \\
\text { ve kortizol } \\
\text { hormonu üzerinde } \\
\text { herhangi bir etki } \\
\text { göstermediği } \\
\text { bulundu }\end{array}$ \\
\hline $\begin{array}{l}\text { (Picciolini ve } \\
\text { ark., 2014) }\end{array}$ & $\begin{array}{l}\text { Vaka } \\
\text { kontrol } \\
\text { çalışması }\end{array}$ & 71 bebek & $30-32$ hafta & $\begin{array}{l}\text { Ses } \\
\text { kayit } \\
\text { cihazı }\end{array}$ & $50 \mathrm{~dB}$ & Anne sesi & $\begin{array}{l}\text { Standart } \\
\text { bakim }\end{array}$ & 30 dakika & $\begin{array}{l}21 \quad \text { gün } \\
\text { boyunca } \\
\text { günde üç } \\
\text { defa }\end{array}$ & \begin{tabular}{l}
\multicolumn{2}{l}{ Fizyolojik } \\
etkiler (kalp \\
atım hızı, \\
satürasyon), \\
vücut \\
aktivitesi, \\
nörofonksiyon \\
aktivitesi
\end{tabular} & $\begin{array}{l}\text { Kalp atımının } \\
\text { stabilleştiği, } \\
\text { satürasyonun } \\
\text { etkilenmediği } \\
\text { belirlendi. } \\
\text { Vücut } \\
\text { aktivitesinde } \\
\text { sadece deri } \\
\text { renginin düzeldiği } \\
\text { bulundu. Üç aylık } \\
\text { dönemde } \\
\text { nörofonksiyon } \\
\text { aktivitesinin } \\
\text { olumlu yönde } \\
\text { etkilendiği } \\
\text { bildirildi. }\end{array}$ \\
\hline $\begin{array}{l}\text { (Zimmerman ve } \\
\text { ark, 2013) }\end{array}$ & $\begin{array}{l}\text { Deneysel } \\
\text { çalışma }\end{array}$ & 32 bebek & 25-33 hafta & $\begin{array}{l}\text { Ses } \\
\text { kayit } \\
\text { cihazı }\end{array}$ & $<65 \mathrm{~dB}$ & Anne sesi & $\begin{array}{l}\text { Standart } \\
\text { bakım }\end{array}$ & 45 dakika & $\begin{array}{l}24 \text { saat } \\
\text { boyunca } \\
\text { günde } \\
\text { dört defa }\end{array}$ & $\begin{array}{l}\text { Kilo alımı, } \\
\text { beslenme }\end{array}$ & $\begin{array}{l}\text { Anne sesinin kilo } \\
\text { alımını etkilediği } \\
\text { bulundu. } \\
\text { Beslenme } \\
\text { volümünün } \\
\text { değişmediği } \\
\text { görüldü. }\end{array}$ \\
\hline (Trabzon, 2013) & $\begin{array}{l}\text { Deneysel } \\
\text { çalışma }\end{array}$ & 30 bebek & Belirtilmedi & $\begin{array}{l}\text { Ses } \\
\text { kayit } \\
\text { cihazı }\end{array}$ & $<50 \mathrm{~dB}$ & $\begin{array}{l}\text { Anne sesi, } \\
\text { bebek } \\
\text { bakımı } \\
\text { sirasında }\end{array}$ & $\begin{array}{l}\text { Standart } \\
\text { bakım }\end{array}$ & $\begin{array}{l}\text { 10-15 } \\
\text { dakika }\end{array}$ & $\begin{array}{l}\text { Beş gün } \\
\text { boyunca, } \\
\text { günde üç } \\
\text { defa }\end{array}$ & $\begin{array}{l}\text { Fizyolojik } \\
\text { etkiler (kalp } \\
\text { atımı, solunum } \\
\text { hızı, ateş), } \\
\text { büyüme } \\
\text { gelişme, stres } \\
\text { ve dinlenme }\end{array}$ & $\begin{array}{l}\text { Anne sesinin } \\
\text { sadece stres ve } \\
\text { dinlenmeyi olumlu } \\
\text { yönde etkilediği } \\
\text { bulundu. }\end{array}$ \\
\hline $\begin{array}{l}\text { (Doheny ve } \\
\text { ark., 2012) }\end{array}$ & $\begin{array}{l}\text { Yar1 } \\
\text { deneysel }\end{array}$ & 14 bebek & 26-32 hafta & $\begin{array}{l}\text { Ses } \\
\text { kayit }\end{array}$ & $55-60 \mathrm{dBA}$ & $\begin{array}{l}\text { Anne sesi } \\
\text { ve anne }\end{array}$ & $\begin{array}{l}\text { Hastanenin } \\
\text { rutin sesi }\end{array}$ & 30 dakika & $\begin{array}{l}\text { Bir gün } \\
\text { boyunca }\end{array}$ & $\begin{array}{ll}\text { Kardiyak } & \text { ve } \\
\text { solunum } & \end{array}$ & $\begin{array}{lr}\text { Anne } & \text { sesinin } \\
\text { kardiyak } & \text { ve }\end{array}$ \\
\hline
\end{tabular}



çalışma
cihaz1
kalp sesi

dört defa

düzenlenmesi

solunum

düzenlemesinde

olumlu katk1 (Krueger ve ark,
2010)

Yar1
deneys
$\begin{array}{lll}\text { 28-34 hafta } & \text { Ses } \\ \text { ve } & 32-34 & \text { kayı }\end{array}$

$58-60 \mathrm{~dB}$

Anne sesi

Standart

Belirtilmedi

Alt1

Alt1

hafta

boyunca

Beslenme,

yaptığ 1 bulundu

çalışma hafta cihazı

günde

beslenme

Anne sesi alan

iki defa

bebeklerin

beslenme

toleransinın

geliştiği ve enteral

beslenmede daha

az kaldıkları tespit edildi

\begin{tabular}{|c|c|c|c|c|c|c|c|c|c|c|c|}
\hline (Cevasco, 2008) & $\begin{array}{l}\text { Deneysel } \\
\text { çalışma }\end{array}$ & 24 bebek & 28-36 hafta & $\begin{array}{l}\text { Ses } \\
\text { kayıt } \\
\text { cihazı }\end{array}$ & $65 \mathrm{~dB}$ & Anne sesi & $\begin{array}{l}\text { Standart } \\
\text { bakım }\end{array}$ & 20 dakika & $\begin{array}{l}\text { İki hafta } \\
\text { boyunca } \\
\text { günde } \\
\text { bir defa }\end{array}$ & $\begin{array}{l}\text { Stres, taburcu } \\
\text { olma }\end{array}$ & $\begin{array}{l}\text { Bebeklerin } \\
\text { stresleri düşük } \\
\text { oranda azalırken } \\
\text { hastanede kalma } \\
\text { sürelerin kısaldığı } \\
\text { görüldü }\end{array}$ \\
\hline $\begin{array}{l}\text { (Bozzette, } \\
\text { 2008) }\end{array}$ & $\begin{array}{l}\text { Zaman } \\
\text { serili yarı } \\
\text { deneysel } \\
\text { çalışma }\end{array}$ & 14 bebek & 31-34 hafta & $\begin{array}{l}\text { Video } \\
\text { kayit } \\
\text { cihazı }\end{array}$ & $65 \mathrm{~dB}$ & Anne sesi & & 3 dakika & $\begin{array}{l}\text { Üç gün } \\
\text { boyunca } \\
\text { günde } \\
\text { dört defa }\end{array}$ & $\begin{array}{l}\text { Stres, } \\
\text { davranışsal ve } \\
\text { fizyolojik } \\
\text { etkiler }\end{array}$ & $\begin{array}{l}\text { Oksijen } \\
\text { satürasyonu ve } \\
\text { kalp atımında } \\
\text { değişiklik } \\
\text { görülmezken } \\
\text { solunum hızı } \\
\text { olumlu etkilendiği } \\
\text { bulundu. Stres } \\
\text { bulgularında } \\
\text { değişiklik } \\
\text { görülmediği ancak } \\
\text { bebeklerde } \\
\text { stabilitenin arttığı } \\
\text { bulundu. } \\
\text { Bebeklerin ağlama } \\
\text { sürelerinin azaldığı } \\
\text { belirlendi }\end{array}$ \\
\hline $\begin{array}{l}\text { (Johnston ve } \\
\text { ark, 2007) }\end{array}$ & Crossover & 20 bebek & 32-36 hafta & $\begin{array}{l}\text { Ses } \\
\text { kayıt } \\
\text { cihazı }\end{array}$ & $60-70 \mathrm{dBA}$ & $\begin{array}{l}\text { Anne sesi, } \\
\text { topuktan } \\
\text { kan alma }\end{array}$ & & Bir dakika & $\begin{array}{l}\text { İki gün } \\
\text { boyunca } \\
\text { her gün } \\
\text { üç defa }\end{array}$ & $\begin{array}{l}\text { Ağrı, } \\
\text { fizyolojik } \\
\text { etkiler (kalp } \\
\text { atım, } \\
\text { satürasyon) } \\
\end{array}$ & $\begin{array}{l}\text { Anne sesinin ağrı } \\
\text { skoru ve fizyolojik } \\
\text { etkiler üzerinde bir } \\
\text { etkisi tespit } \\
\text { edilemedi }\end{array}$ \\
\hline (Blumenfeld ve & Pilot yarı & 11 bebek & 31-40 hafta & Anneni & $60-79 \mathrm{~dB}$ & Anne sesi, & & Bebek & İki gün & Beslenme, & Beslenme \\
\hline
\end{tabular}




\begin{tabular}{|c|c|c|c|c|c|c|c|}
\hline Eisenfeld, 2006) & $\begin{array}{l}\text { deneysel } \\
\text { çalışma }\end{array}$ & $\begin{array}{l}\text { canl1 } \\
\text { sesi }\end{array}$ & beslenme & $\begin{array}{l}\text { beslenmesi } \\
\text { boyunca }\end{array}$ & $\begin{array}{l}\text { boyunca } \\
\text { günde } \\
\text { iki defa }\end{array}$ & $\begin{array}{l}\text { fizyolojik } \\
\text { etkiler (kalp } \\
\text { atım, solunum }\end{array}$ & $\begin{array}{l}\text { fizyolojik } \\
\text { parametrelerde } \\
\text { hiçbir değişiklik } \\
\text { tespit edilmedi }\end{array}$ \\
\hline
\end{tabular}

* Randomize kontrollü çalışma, ** Desibel adjusted

\section{Bulgular}

\section{Çalışmaların genel özellikleri}

Araștırma kapsamına alınan çalışmalar genel olarak randomize kontrollü çalışma, deneysel ve yarı deneysel çalışmalardan oluşmaktaydı. Geri kalanlar ise kohort, vaka çalışması ve çapraz tasarımda düzenlenmişti. ${ }^{13,19,20}$ Çalışmalarda gestasyon yaşı farklılık göstermekteydi. İki çalışmada gestasyon yaşının belirlenemediği bildirilmişti. ${ }^{71}$ Çalışmalarda uygulama aşamasında ses kayıt cihazı, MP3 player ya da CD çalar gibi cihazlar kullanıldığı belirlendi. Bir çalışmada ise beslenme sırasında canlı olarak anne tarafından bebeğe şarkı söylendiği ve herhangi bir cihaz kullanılmadı̆̆ 1 tespit edildi. ${ }^{10}$

Araştırma kriterleri kapsamında çalışmaya dahil edilen 4 çalışmada bebeklere dinletilen sesin $50 \mathrm{~dB}$ üzerinde olduğu tespit edildi. ${ }^{4,15,19}$ Yapılan bir çalıșmada ise kullanılan sesin desibel aralığı belirtilmedi. ${ }^{11}$ İki çalışmada ${ }^{12,16}$ anne sesi ile beraber anne kalp sesi de dinletildiği, diğer çalışmalarda sadece anne sesi kullanıldığı belirlendi.

Çalışmalarda anne sesi ve kalp sesinin kullanımının işlem, süre ve sıklığı oldukça değişkenlik göstermekteydi. Jonston ve ark., ${ }^{13}$ çalışmasında, anne sesi maruziyet süresi bir dakika iken, Dorn ve ark., ${ }^{21}$ çalışmasında bu süre bir saat olarak belirtilmişti. Benzer şekilde araştırma kapsamına alınan bir çalışmada ${ }^{22}$ anne sesi yalnızca bir kez, başka bir çalışmada ${ }^{14}$ altı hafta boyunca günde iki kez uygulanmıştı. Dört çalışmada ${ }^{4,7,10,22}$ anne sesinin sadece işlem sırasında uygulandığ ve anne sesinin sakinleştirici özelliğinden yararlanıldı ̆̆ı belirlendi.

\section{Anne sesi ve anne kalp sesinin etkileri}

\section{Ăgrı}

Çalışmalarda anne sesinin ağrı üzerine etkisinin farkl1lık gösterdiğ belirlendi. Buna göre; üç çalışmada bebeğe işlem uygulanırken anne sesi dinletildiği ve bu işlemlerin venöz ve topuktan kan alma işlemleri olduğu belirtildi. ${ }^{7,13,22}$ Alemdar ${ }^{7}$, Johnston ve ark.'nın çalışmasında ${ }^{13}$, ağrı skoru değişmezken, Chirico ve ark.'nın çalışmasında ${ }^{22}$, deney grubunda yer alan bebeklerin ağrısının düştüğü belirlendi.

\section{Fizyolojik özellikler}

İncelenen çalışmaların sekizi anne sesi ve anne kalp sesinin bebeklerin fizyolojik özelliklerine etkisini incelemekteydi. Bunlar kalp atımı hızı, solunum hızı ve oksijen satürasyonu idi. İlgili çalışmaların bulguları incelendiğinde fizyolojik parametrelerin farklı sonuçlar gösterdiği belirlendi. Buna göre; Johnston ve ark., ${ }^{13}$ Trabzon $^{15}$ ve Blumenfeld ve ark.'nın çalışmalarında ${ }^{10}$ anne sesi ve anne kalp sesinin fizyolojik özellikler üzerine hiçbir etkisinin olmadığı, Alemdar ve ark., ${ }^{4}$ Picciolini ve ark.'nın çalışmalarında ${ }^{19}$ ise satürasyon seviyesinin yükseldiği ve Rand ve ark., ${ }^{20}$ ile Picciolini ve ark.'nın çalışmalarında ${ }^{19}$ kalp atımının stabilleştirdiği belirlendi. Bir çalışmada ${ }^{12}$, anne sesinin kardiyorespiratuar sistemi olumlu etkilediği tespit edildi. Farklı bir çalışma sonucunda ise uzun süre anne sesi dinletilen bebeklerin deri renginin düzeldiği belirlendi. ${ }^{19}$

\section{Beslenme}

Anne sesi ve anne kalp sesinin beslenme üzerine etkisinin incelendiği dört çalışmanın üçünde ${ }^{11,14,17}$ bu seslerin olumlu etkileri olduğu belirtilirken, Blumenfeld ve ark.'nın çalışmasında ${ }^{10}$ anlamlı bir farkın bulunamadığı belirlendi. Çalışma sonuçlarına göre anne sesi dinletilen bebeklerin oral alımının erken başladığ 1 ve enteral beslenmenin daha kısa sürdüğ̈ görüldü. ${ }^{11,14}$ Zimmerman ve ark.'nın 
çalışmasında ${ }^{17}$ ise sürekli anne sesi dinletilen bebeklerin kilo alımının daha hızlı olduğu bildirildi.

\section{Davranış ve stres}

Anne sesinin bebeklerde uyku-uyanıklık, dinlenme, ağlama ve stres üzerine etkisini inceleyen dört çalışmaya ulaşıldı. ${ }^{15,21,23,24}$ Dorn ve ark.'nın çalışmasında ${ }^{21}$ anne sesi dinletilen bebeklerin uyku süresinin uzadığ 1 ve uyku döngülerin daha stabil olduğu belirlendi. Trabzon ${ }^{15}$, Bozzette ve ark.'nın çalışmalarında ${ }^{23}$ bebeklerin dinlenme sürelerin daha uzun olduğu ve daha az ağladıkları tespit edildi. Stres bulguları incelenen üç çalışmanın ikisinde ${ }^{15,24}$ bebeklerin streslerin azaldiğ 1 belirtildi. Bir çalışmada $^{23}$ çocukların stres seviyelerinin değişmediği görüldü.

\section{Beyin gelişimi}

Anne sesinin bebeklerin beyin gelişimi ve nörofonsiyon aktivitesi üzerine etkisini inceleyen iki çalışmaya ${ }^{16,19}$ ulaşıldı. Beyin görüntülerinin incelendiği Webb ve ark.'nın çalışmasında ${ }^{16}$ anne sesi dinletilen bebeklerin olumlu etkilendikleri belirlendi. Picciolini ve ark.'nın çalışmasında ${ }^{19}$ ise deney grubu bebeklerin üç aylık dönemde nörofonksiyon aktivitelerinin düzeldiği tespit edildi.

\section{Tartışma}

$\mathrm{Bu}$ araştırma; anne sesi ve anne kalp sesinin bebekler üzerine olan etkisini inceleyen çalışmaları özetlemek amacıyla yapılmıştır. Buna göre, anne sesi ve anne kalp sesinin bebeğin ağrı, konfor, fizyolojik parametreleri, beslenme, davranış, stres ve beyin gelişimi üzerine etkisini belirleyen çalışmalar incelenmiştir.

Çalışmaların sadece ikisinde ${ }^{12,16}$ anne kalp sesi kullanıldığı, her ikisinde de anne kalp sesi ve anne sesinin birlikte verildiği görülmüştür. Kalp sesi gibi ritimli seslerin bebeklerin dikkatini çektiği ve onları sakinleştirdiği bildirilmiştir. ${ }^{3}$ Buna neden olan durumun güvenli intrauterin hayatta bebeklerin bu sese maruz kalması ve sesi tanıması sonucunda, kendini güvende hissetmesi nedeniyle olduğu düşünülmektedir. ${ }^{25,26}$
Ağrıyı inceleyen üç çalışmada ${ }^{7,13,22}$ farklı sonuçlar elde edildiği belirlenmiştir. $\mathrm{Bu}$ çalışmaların klinik prosedürleri birbirinden farklılık göstermektedir. Johnston ve ark. ${ }^{13}$ 'nın çalışmasında, topuktan kan alma işlemi için anne sesi yalnızca bir dakika boyunca dinletmiştir. Benzer şekilde Alemdar ${ }^{7}$, venöz girişim için 16 dakika boyunca anne sesi dinletmiştir. $\mathrm{Bu}$ çalışmaların ikisinde anne sesinin ağrı üzerine etkisiz olduğu bulunurken Chirico ve ark. $^{22}$ 'nın çalışmasında ise topuktan kan alma işlemi için anne sesi 30 dakika boyunca dinletilmiş ve ağrının azaldığı tespit edilmiştir.

$\mathrm{Bu}$ çalışmalarda, anne sesi maruziyetinin desibel düzeyi, süre ve sıklığı, bebeğe uygulanan ağrılı işlemlerin ve bebeklerin gestasyon haftaların standart olmamasina bağlı olarak farklı sonuçların elde edildiği düşünülmektedir. Aynı zamanda ağrı gibi nörobilişsel açıdan zorlayıcı durumlarda, bebeklere sadece anne sesinin dinletilmiş olmasının yetersiz kalacağı, anne kokusu ile dokunma gibi uyaranlarla uygulanan girişimlerin desteklenmesi gerektiği bildirilmiştir. $^{27}$

Anne sesi ve anne kalp sesinin bebekler üzerinde fizyolojik etkilerinin incelendiği çalışmalarda ${ }^{4,7,10,12,20}$ tutarsız sonuçlar elde edildiği görülmüştür. Sonuçların özellikle gestasyon yaşı ve bunun yanında, anne sesi düzeyi, süre ve sıklığı gibi birçok faktörden etkilenme durumu olabilir. 32 haftadan önce doğan bebeklerin beyin fonksiyonlarının yetersiz olmasi nedeniyle anne sesinin sonuçları daha az etkilediği düşünülebilir. ${ }^{28}$ Anne sesinin bir ayda 24 gün boyunca ve günde dört defa dinletildiği bir çalışma ${ }^{20}$ ile 21 gün boyunca her gün günde üç defa dinletildiği başka bir çalışmada ${ }^{13}$ bebeklerde önemli değişikliklerin görüldüğü belirlenmiştir. Bu nedenle, çalışmalarda anne sesinin uzun süre dinletilmesinin bebekte önemli değişikler yapacağı düşünülmektedir. Nitekim bir ay boyunca günde dört defa ve her defasinda 45 dakika anne sesinin dinletildiği ve bebeklerin beyin gelişiminin incelendiği başka bir çalışmada ${ }^{16}$ önemli olumlu sonuçlar elde edildiği gözlenmiştir. Picciolini ve ark.'nın çalışmasında ${ }^{19}, 21$ gün 
boyunca günde üç defa ve 30'ar dakika boyunca anne sesi dinletmiş nörofonksiyon aktivite ve fizyolojik parametrelerin olumlu etkilendiği vurgulanmıştır.

Anne sesinin bebek beslenmesine etkisiyle ilgili çalışmalarda ${ }^{11,14,17}$ bebeklerin oral beslenmesinin geliştiği, kilo alımının desteklendiği ve enteral beslenmenin erken sonlandığ 1 bildirilmiştir. Ancak bebeğin emzirilmesi sirasinda anne sesinin canlı olarak ve 60-79 dB aralığında dinletildiği bir çalışmada ${ }^{10}$ anne sesinin beslenme üzerinde bir etkisinin olmadığ 1 belirlenmiştir. $\mathrm{Bu}$ çalışmada annelerin bebeklerinin bulunduğu durumdan dolayı çok kaygılı olduğu ve şark1 söylerken çok gerildikleri bildirilmiştir. $\mathrm{Bu}$ bağlamda, yapılan bir çalışmaya ${ }^{29}$ göre anne kaygısının bebeği olumsuz etkilediği ve bu çalışmada da buna benzer bir etki yarattığ düşünülmektedir. Aynı zamanda APA'nın önerdiği $50 \mathrm{~dB}$ ses seviyesine ${ }^{4}$ rağmen bu çalışmada anneler yüksek ses ile şark1 söylemiştir. Yüksek sesin bebeği rahatsız edebileceği göz ardı edilmemelidir.

Bazı çalışmalarda anne sesinin bebeğin uyku-uyanıklık, dinlenme, ağlama ve stres üzerine etkisi incelenmiştir. Çalışma sonuçlarında bebeklerin daha uzun süre uyudukları, aktivitelerinin arttığı, etkili dinlendikleri ve stres bulgularının azaldığ bulunmuştur. ${ }^{15,21,23,24}$ Bebeklerin 26-28. haftalarda anne sesini kemik iletim yoluyla duyabildiği ${ }^{8}$ anne sesini tanıyabildiği ve buna tepki verebildiği belirtilmektedir. Bu nedenle, anne sesi dinletilen bebeklerin 28 haftadan büyük oldukları için anne sesini algılayabilecekleri, bunun sonucu olarak endorfin salgilayabilecekleri ve daha stabil kalabilecekleri düşünülebilir. Yalnızca bir çalışmada $^{23}$ anne sesinin bebeğin stresini etkilemediği bildirilmiştir. Diğer çalışmaların aksine bu çalışmada anne sesi dinletim süresinin üç dakika olduğu ve sıklığının diğer çalışmalara göre daha az olduğu belirlenmiştir. Uzun süre anne sesi maruziyetinin bebeklerin davranış ve stresini olumlu yönde etkilediği söylenebilir.

\section{Sonuç}

Araştırma kapsamına alınan çalışmalarda anne sesi ve anne kalp sesinin bebekler üzerine etkisi incelenmiştir. Tek başına anne kalp sesinin etkinliği ile ilgili bir sonuç belirlenememiştir. Çalışmalarda oldukça farklı klinik deneme sonuçları, gestasyon yaşı, ses düzeyi, anne sesi maruziyet süresi ve sıklığı olduğu tespit edilmiştir. Bunun yanı sıra anne sesinin bebeklerde ağrı, konfor ve fizyolojik özellikler üzerinde kesin sonuçları bulunmadığ 1 gözlenirken iyi düzenlenmiş klinik denemelerde anne sesinin beslenme, stres, davranış ve beyin gelişimi üzerinde etkili olduğu görülmüştür.

$\mathrm{Bu}$ bilgiler çerçevesinde çalışmalara alınacak bebeklerin gestasyon yaşı, bebeğe uygulanan işlem, anne sesinin süre ve sıklığg, anne sesinin desibel düzeyi ve uygulama şeklinin iyi seçilmesi gerektiği düşünülmektedir. 26-28 haftadan önce doğan yenidoğan bebeklerin anne sesini kavrayamayacakları göz önüne alınmalıdır. Ayrıca klinik denemelerde zamanlama ve süre iyi seçilmelidir. Çok ağrılı işlemlerde anne sesi ile beraber anne kokusu ve annenin dokunması sağlanmalıdır. Yüksek ses düzeyinde anne sesi dinletilmesinden kaçınılmalıdır. Bunun bebeği olumsuz etkileyeceği düşünülmelidir.

Yenidoğan yoğun bakım ortamında yüksek riskli olan yenidoğanlara anne ve/veya babanın dokunma imkanı olmayabilir. Ayrıca ebeveynler bu süreçte kendini iyi ve konforlu hissetmeyebilir. Bundan dolayı iyi düzenlenmiş, önerilen ses desibel düzeyindeki anne sesinin kayıt cihazı ile bebeğe dinletilmesi de önerilebilir.

Anne sesinin nasıl dinletilmesi ve protokolün nasıl olması gerektiği ile ilgili rehberler hazırlanmalı ve yenidoğan yoğun bakımlarda uygulanmalıdır.

\section{Araştırmanın Sınırlılıkları}

Araştırma kapsamına alınıp değerlendirilen bazı çalışmaların dili İngilizce ve Türkçe dışında olduğundan bu çalışmaların sonuçları değerlendirilememiştir. 2005'ten önce yayımlanan çalışmalar, değerlendirilmeye alınmamıştır. Bunun yanı sıra, çalışmaların klinik düzen ve parametreler farklılık gösterdiğinden uygulamaların etkinliğine dair kesin bir sonuca varılamamıştır. 


\section{Çıkar Çatışması Beyanı}

Yazarların herhangi bir çıkar çatışması bulunmamaktadır.

\section{Araştırma Desteği}

Çalışmayı maddi olarak destekleyen kişi/kuruluş yoktur.

\section{Hakem Değerlendirmesi}

Dış bağımsı.

\section{Beyanlar}

Çalışma daha önce herhangi bir yerde sunulmamıştır.

\section{Kaynaklar}

1. Als H, Duffy FH, McAnulty G, et al. NIDCAP improves brain function and structure in preterm infants with severe intrauterine growth restriction. Journal of Perinatology. 2012;32(10):797-803.

2. İncekar MÇ, Gözen D. Preterm bebeklerde bireyselleștirilmiș gelişimsel bakım. Journal of Health and Sport Sciences. 2019;2(1):16-21.

3. Arpacı T, Altay N. Yenidoğan yoğun bakım ünitelerinde bireyselleştirilmiş gelişimsel bakım: güncel yaklaşımlar. Turkiye Klinikleri J Nurs Sci. 2017;9(3):245-54.

4. Alemdar DK, Tüfekci FG. Effect of maternal heart sounds on physiological parameters in preterm infants during aspiration. Kontakt. 2017;19(2):e99-104.

5. Konkani A, Oakley B. Noise in hospital intensive care units-a critical review of a critical topic. Journal of Critical Care. 2012;27(5):522.e1-9.

6. Provenzi L, Broso S, Montirosso R. Do mothers sound good? A systematic review of the effects of maternal voice exposure on preterm infants' development. Neuroscience \& Biobehavioral Reviews. 2018;88:42-50.

7. Alemdar DK. Effect of recorded maternal voice, breast milk odor, and incubator cover on pain and comfort during peripheral cannulation in preterm infants. Applied Nursing Research. 2018;40:1-6.

8. Voegtline KM, Costigan KA, Pater HA, DiPietro JA. Nearterm fetal response to maternal spoken voice. Infant Behavior and Development. 2013;36(4):526-33.

9. Çağlar S, Dur Ş, Sönmez Düzkaya D, Koç Özkan T, Torun N, Çiğdem Z, Yıldız S, Balcı S, Gözen D, Kerimoğlu Yıldız G. Türkiye'deki yenidoğan hemșirelerinin profilleri ve bireyselleştirilmiş gelişimsel bakıma yönelik uygulamaları. JAREN. 2019;5(2):132-40.

10. Blumenfeld H, Eisenfeld L. Does a mother singing to her premature baby affect feeding in the neonatal intensive care unit? Clinical Pediatrics. 2006;45(1):65-70.

11. Chorna OD, Slaughter JC, Wang L, Stark AR, Maitre NL. A pacifier-activated music player with mother's voice improves oral feeding in preterm infants. Pediatrics. 2014;133(3):462-8.

12. Doheny L, Hurwitz S, Insoft R, Ringer S, Lahav A. Exposure to biological maternal sounds improves cardiorespiratory regulation in extremely preterm infants. The Journal of Maternal-Fetal \& Neonatal Medicine. 2012;25(9):1591-4.

13. Johnston CC, Filion F, Nuyt AM. Recorded maternal voice for preterm neonates undergoing heel lance. Advances in Neonatal Care. 2007;7(5):258-66.

14. Krueger C, Parker L, Chiu S, Theriaque D. Maternal voice and short-term outcomes in preterm infants. Developmental Psychobiology: The Journal of the International Society for Developmental Psychobiology. 2010;52(2):205-12.

15. Trabzon B. Anne Sesinin Prematüre Bebekler Üzerindeki Etkisi [Yüksek Lisans Tezi]. İstanbul: Haliç Üniversitesi; 2013.

16. Webb AR, Heller HT, Benson CB, Lahav A. Mother's voice and heartbeat sounds elicit auditory plasticity in the human brain before full gestation. Proceedings of the National Academy of Sciences. 2015;112(10):3152-7.

17. Zimmerman E, Keunen K, Norton M, Lahav A. Weight gain velocity in very low-birth-weight infants: effects of exposure to biological maternal sounds. American Journal of Perinatology. 2013;30(10):863-70.

18. Jackson, N, Waters E. Criteria for the systematic review of health promotion and public health interventions. Health Promotion International. 2005;20(4):367-74.

19. Picciolini O, Porro M, Meazza A, et al. Early exposure to maternal voice: effects on preterm infants development. Early Human Development. 2014;90(6):287-92.

20. Rand K, Lahav A. Maternal sounds elicit lower heart rate in preterm newborns in the first month of life. Early Human Development. 2014;90(10):679-83.

21. Dorn F, Wirth L, Gorbey S, et al. Influence of acoustic stimulation on the circadian and ultradian rhythm of premature infants. Chronobiology International. 2014;31(9):1062-74.

22. Chirico G, Cabano R, Villa G, Bigogno A, Ardesi M, Dioni E. Randomised study showed that recorded maternal voices reduced pain in preterm infants undergoing heel lance procedures in a neonatal intensive care unit. Acta Paediatrica. 2017;106(10):1564-8.

23. Bozzette M. Healthy preterm infant responses to taped maternal voice. The Journal of Perinatal \& Neonatal Nursing. 2008;22(4):307-16.

24. Cevasco AM. The effects of mothers' singing on full-term and preterm infants and maternal emotional responses. Journal of Music Therapy. 2008;45(3):273-306.

25. Ciccone A. Rhythmicity in infants' experiences and their development. Journal of Physiology-Paris. 2013;107(4):28690.

26. Suppanen E, Huotilainen M, Ylinen S. Rhythmic structure facilitates learning from auditory input in newborn infants. Infant Behavior and Development. 2019;57:101346.

27. Bucsea O, Riddell RP. Non-pharmacological pain management in the neonatal intensive care unit: managing neonatal pain without drugs. Seminars in Fetal and Neonatal Medicine. 2019;24(4):101017.

28. Glass HC, Costarino AT, Stayer SA, Brett C, Cladis F, Davis PJ. Outcomes for extremely premature infants. Anesthesia and Analgesia. 2015;120(6):1337.

29. Nicol-Harper R, Harvey AG, Stein A. Interactions between mothers and infants: impact of maternal anxiety. Infant Behavior and Development. 2007;30(1):161-7.

30. Mooncey S, Giannakoulopoulos X, Glover V, Acolet D, Modi $\mathrm{N}$. The effect of mother-infant skin-to-skin contact on plasma cortisol and $\beta$-endorphin concentrations in preterm newborns. Infant Behavior and Development. 1997;20(4):553-7. 